\title{
Predictors of early recurrence after resection of colorectal liver metastases
}

\author{
Ricky Harminder Bhogal ${ }^{1,2^{*}}$, James Hodson', Simon Roderick Bramhall', John Isaac ${ }^{1}$, Ravi Marudanayagam', \\ Darius Feroze Mirza', Paolo Muiesan ${ }^{1}$ and Robert Peter Sutcliffe ${ }^{1}$
}

\begin{abstract}
Background: Early recurrence after resection of colorectal liver metastases (CLM) is common. Patients at risk of early recurrence may be candidates for enhanced preoperative staging and/or earlier postoperative imaging. The aim of this study was to determine if there are any risk factors that specifically predict early liver-only and systemic recurrence.

Methods: Retrospective analysis of prospective database of patients undergoing liver resection (LR) for CLM from 2004 to 2006 was undertaken. Early recurrence was defined as occurring within 18 months of LR. Patients were classified into three groups: early liver-only recurrence, early systemic recurrence and recurrence-free. Preoperative factors were compared between patients with and without early recurrence.

Results: Two hundred and forty-three consecutive patients underwent LR for CLM. Twenty-seven patients (11\%) developed early liver-only recurrence. Dukes $C$ stage and male sex were significantly associated with early liver-only recurrence $(P<0.05)$. Sixty-six patients $(27 \%)$ developed early systemic recurrence. Tumour size $\geq 3.6 \mathrm{~cm}$ and tumour number $(>2)$ were significantly associated with early systemic recurrence $(P<0.001)$.

Conclusions: It is possible to stratify patients according to the risk of early liver-only or systemic recurrence after resection of CLM. High-risk patients may be candidates for preoperative MRI and/or computed tomography-positron emission tomography (CT-PET) scan and should receive intensive postoperative surveillance.
\end{abstract}

\section{Background}

The liver and lungs are the most frequent sites of distant metastases from colorectal cancer (CRC). Following diagnosis, $50 \%$ to $60 \%$ of patients with CRC will develop colorectal liver metastasis (CLM) [1], and 11\% will develop pulmonary metastasis [2]. Surgical resection is the most effective treatment for CRC that has metastasized to the liver [3] or lung [4]. Indeed, in selected patients, liver resection (LR) for CLM has yielded a median 5-year survival rate of $25 \%$ to $58 \%[3,5,6]$ and a median 5 -year survival of $45 \%$ to $60 \%$ for solitary liver metastasis [3]. However, recurrence after resection of colorectal liver metastases is common, developing in the liver remnant

\footnotetext{
* Correspondence: balsin@hotmail.com

${ }^{1}$ University Hospitals of Birmingham, Metchley Lane, Birmingham, West Midlands B15 2TT, UK

${ }^{2}$ Centre for Liver Research, Institute for Biomedical Research, The Medical School, University of Birmingham, Edgbaston, Birmingham, West Midlands
} B15 2T, UK

\section{Biomed Central}

in up to $30 \%$ of patients $[7,8]$ and at extra-hepatic locations in up to $50 \%$ [9-12].

Despite surgical resection, the relatively high recurrence rate is likely due to occult micro-metastases. Local and/or systemic recurrence may develop within months to years after LR [13]. Early recurrence may be due to aggressive tumour biology, inadequate surgical resection and/or failure of systemic therapy and may also be an indication of suboptimal pre-operative staging. There are currently no universally agreed protocols for either preoperative imaging before LR or for surveillance postoperatively [14]. Contrast-enhanced computed tomography (CT) is the imaging modality of choice for staging patients with liver metastases and for postoperative monitoring. Magnetic resonance imaging (MRI) has a higher sensitivity than CT in detecting liver metastases, particularly when used with liver-specific contrast [15], but is not routinely performed in many centres [16]. Similarly, the role of fluorodeoxyglucose (FDG) positron emission 
tomography (PET) or CT-PET to identify extra-hepatic disease before LR remains unproven [17].

The risk factors for recurrence after LR are well documented and relate to the biology and stage of the primary tumour, the burden of liver metastases and the response to chemotherapy $[3,5,18]$. Recent studies have suggested factors that may predict early recurrence after liver resection for CLM. Vigano et al. have shown that T3-T4, synchronous CLM and limited resection margins increase the risk of recurrence [19]. In addition, the same group showed that adjuvant chemotherapy reduced recurrence rates. Other authors have suggested that the number of liver metastases predicts early recurrence [13]. These particular subgroup of patients may benefit from enhanced pre-operative staging and/or intensive post-operative surveillance in the early post-operative period.

Patients at risk of early recurrence may also benefit from neoadjuvant or adjuvant chemotherapy. The aim of this study was to identify predictors of early liver-only or systemic recurrence after resection of CLM.

\section{Methods}

\section{Patients and data collection and statistical analysis}

We reviewed our prospectively held departmental database to identify all patients who had undergone LR for CLM between January 2004 and December 2006 inclusive. Two hundred forty-three patients were identified. Patients were considered for LR after clinical evaluation and pre-operative staging with a chest, abdominal and pelvic CT scan. All patients were discussed within a specialist hepatobiliary multidisciplinary team meeting. MRI was performed selectively in patients with advanced primary tumours (T4 or N2) or synchronous metastases. CT-PET was performed in selected patients to assess any suspicious extra-hepatic lesions detected by CT.

After initial LR, patients underwent regular clinical assessment, serial serum CEA measurement and surveillance CT scans at 1 and 2 years postoperatively. In this study, early recurrence was defined by the presence of either liver-only or systemic (with or without liver involvement) disease within 18 months after liver resection. Eighteen months was selected as a cut-off based on an analysis of the timing and pattern of postoperative recurrence in the entire cohort. The reason for opting for this time period is illustrated in Figure 1. Most liver-only and systemic recurrence occurred with 18 months following LR.

It is unlikely that enhanced preoperative staging (that is, MRI and/or CT-PET) would detect additional sites of disease in patients who subsequently develop recurrence beyond 18 months after surgery. Potential risk factors for early recurrence were identified including clinical, radiological and pathological parameters: age, gender,

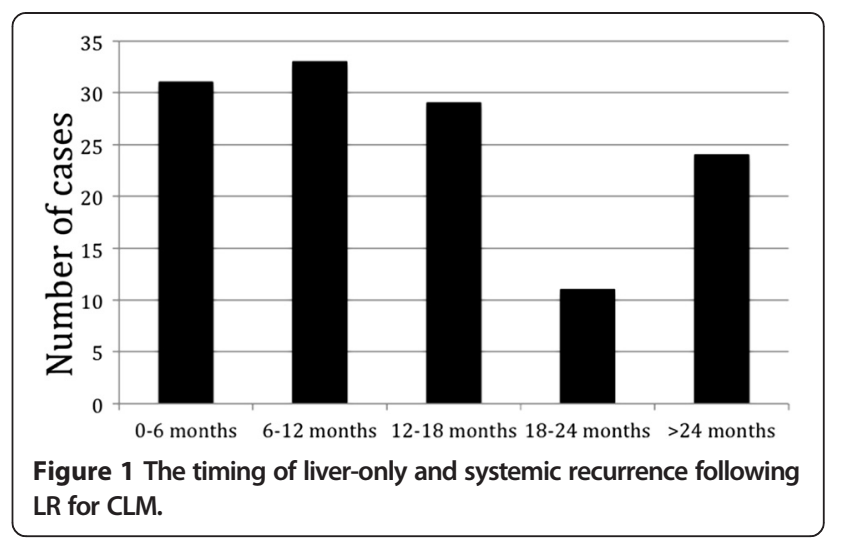

site and nodal status of the primary CRC, the size and number of hepatic tumours. Pre-operative CEA was not included in the analysis due to incomplete data. Initially, for the purposes of analysis, a range of variables was compared between the three study groups (No recurrence/ Liver recurrence/Systemic recurrence). For the continuous variables, a Kruskal-Wallis test was performed to test for variations between the three groups. Where this was significant, post hoc pairwise tests were performed between the non-recurrence group and both recurrence groups, in order to test for significant differences. A similar approach was applied to the binary variables in which a Fisher's exact test was performed on all three groups initially, with post hoc tests used to compare the non-recurrent patients with patients in the other two groups. Patient survival was calculated using Kaplan-Meier estimates. $P$ values $<0.05$ were considered statistically significant.

\section{Results}

In this study, 243 patients underwent LR of CLM with curative intent between January 2004 and December 2006 inclusive. Table 1 shows the overall demographics of the study population.

At a median follow-up of 58 months (range 33 to 74 months), 93 patients (38\%) developed early recurrence (defined as within 18 months of surgery), including 27 patients (11\%) with liver-only recurrence and 66 patients $(27 \%)$ with systemic recurrence (with or without liver recurrence). Thirty-five patients (14\%) developed late recurrence and 115 patients (47\%) were recurrencefree at follow-up (Table 2). Median times to diagnosis of recurrence in patients with liver-only recurrence and systemic recurrence were similar: 11 [6-14] vs. 9.5 [6-14] months $(P=0.841)$. In patients with early liver-only recurrence, 19 patients $(70 \%)$ had treatable lesions (repeat LR 11, radiofrequency ablation 8), and 8 patients were suitable for palliative treatment only. Seventeen patients (26\%) with early systemic recurrence were amenable to further surgery (pulmonary metastasectomy, $N=13$ ) or ablation $(N=4)$. Twenty-seven patients $(41 \%)$ received 
Table 1 The overall patient demographics in the study
population

Parameters

Age at time of LR

$\leq 65$

$>65$

Gender

Male

Female

Site of primary CRC

Colon

Rectum

Dukes stage of primary CRC

Dukes A

Dukes B

Dukes C

Adjuvant chemotherapy

Yes

No

Number of metastasis

1

2

3

$\geq 3$

Distribution of metastasis

Unilobar

Bilobar

Extra-hepatic disease

Yes

No

Post-op resection status

RO

R1

R2

Type of LR

Minor

Major

palliative chemotherapy and the remaining 22 (33\%) were suitable for best supportive care only. Five-year overall and disease-free survival rates in the entire cohort were $47 \%$ and $42 \%$, respectively. Median survival in patients with disease recurrence (liver or systemic) was 6.5 months (range 2 to 26 months). As expected, disease recurrence was associated with significantly worse overall survival (Figure 2).

Analysis of our patient cohort revealed that male patients and advanced stage primary tumours (Dukes C) were significant risk factors for early liver-only recurrence (see Table 3). Early systemic recurrence was more likely in patients with a high burden of liver metastases (tumour diameter $>3.6 \mathrm{~cm}$ or tumour number $\geq 2.3$ ).

\section{Discussion}

In an era of modern chemotherapy, surgical resection of CLM can be justified and may yield long-term survival in selected patients [20-22]. However, disease recurrence after LR is common and negatively impacts on patient survival $[13,18,22]$. Disease recurrence presumably reflects the presence of viable tumour deposits that are undetected by conventional pre-operative CT [23]. MRI is increasingly being utilized to characterize benign and malignant liver lesions [14,24-26] and appears to be more sensitive than CT, particularly when used with liver-specific contrast agents [14]. The potential advantages of MRI over CT are particularly evident in patients with background hepatic steatosis after chemotherapy [27]. However, at present, there is insufficient evidence to justify the routine use of MRI prior to LR for CLM. Risk factors for early recurrence after LR have been suggested previously such as multiple (>8) CLM [13] with recurrence within the liver being the commonest cause of treatment failure [28]. However, no studies have identified factors that specifically predispose to early liver-only or systemic recurrence. Previous multivariate analysis has revealed node positive primary tumours, advanced $\mathrm{T}$ stage, presence of extrahepatic disease, CEA >200 ng/ml, multiple tumours, tumour size $>5 \mathrm{~cm}$ and short disease-free interval as predictors for early recurrence and poor overall survival $[5,18,29,30]$. Using this data, a clinical risk score was created to help predict which patients will benefit most from surgical intervention [5]. The current study expands these known risk factors by clearly demonstrating that larger and multiple tumours increase the risk of early systemic recurrence and male gender and advanced CRC predispose to early liver-only recurrence after LR.

The first aim of our study was to determine if there are any preoperative risk factors that may predispose patients to tumour recurrence within the liver remnant specifically within the early post-operative period. On analysis, male sex and advanced primary tumours (Dukes C) increased the risk of early liver-only recurrence. Such patients may be candidates for pre-operative MRI, and they may also benefit from enhanced postoperative surveillance. Early post-operative imaging (CT or MRI) in high-risk patients may identify liver-only recurrence at an earlier, treatable stage, which may potentially influence long-term survival although there remains no conclusive data from the available literature. Other groups also investigating the risk factors for CLM recurrence after LR have failed to show any affect of gender unlike the reported study [31]. 
Table 2 Demographics of patients with no recurrence and those with liver-only and systemic recurrence

\begin{tabular}{|c|c|c|c|c|}
\hline & & $\begin{array}{l}\text { No recurrence } \\
(n=115)\end{array}$ & $\begin{array}{l}\text { Early liver-only recurrence } \\
(n=27)\end{array}$ & $\begin{array}{l}\text { Early systemic recurrence } \\
(n=66)\end{array}$ \\
\hline Male-female ratio & & 1:0.4 & 1:0.13 & 1:0.4 \\
\hline Age (years) & & 65 & 67 & 66 \\
\hline (Quartiles) & & (56 to 71$)$ & (65 to 73 ) & (58 to 71$)$ \\
\hline \multirow[t]{2}{*}{ Primary tumour site CRC (\%) } & Colon & 63 & 71 & 70 \\
\hline & Rectum & 37 & 29 & 30 \\
\hline \multirow[t]{3}{*}{ Primary tumour stage (\%) } & Dukes A & 11 & 0 & 4 \\
\hline & Dukes B & 25 & 4 & 22 \\
\hline & Dukes C & 64 & 96 & 74 \\
\hline Chemotherapy after colectomy (\%) & & 92 & 90 & 94 \\
\hline \multirow[t]{3}{*}{ Pre-operative staging modality (\%) } & $C T$ & 94 & 96 & 91 \\
\hline & MRI & 5 & 4 & 7 \\
\hline & Other & 1 & 0 & 2 \\
\hline \multirow[t]{3}{*}{ Post-operative staging modality } & $\mathrm{CT}$ & 88 & 91 & 87 \\
\hline & MRI & 10 & 9 & 10 \\
\hline & Other & 2 & 0 & 3 \\
\hline
\end{tabular}

The precise reasons underlying this male preponderance remain unclear.

The second aim of our study was to identify any potential risk factors that predict systemic recurrence specifically in the early post-operative period. Our data has indicated that patients with multiple tumours (three or more) or tumours greater than $3.6 \mathrm{~cm}$ are at high risk of early systemic recurrence. This group of patients is unlikely to benefit from LR as an isolated strategy and should be considered for pre-operative CT-PET and systemic chemotherapy. Using this approach, some patients with detectable FDG avid extra-hepatic disease may be spared from futile liver surgery [32]. PET/CT produces a fusion image combining conventional cross-sectional, anatomical imaging of $\mathrm{CT}$ with the biological, functional imaging of PET [33]. It can be utilized successfully to

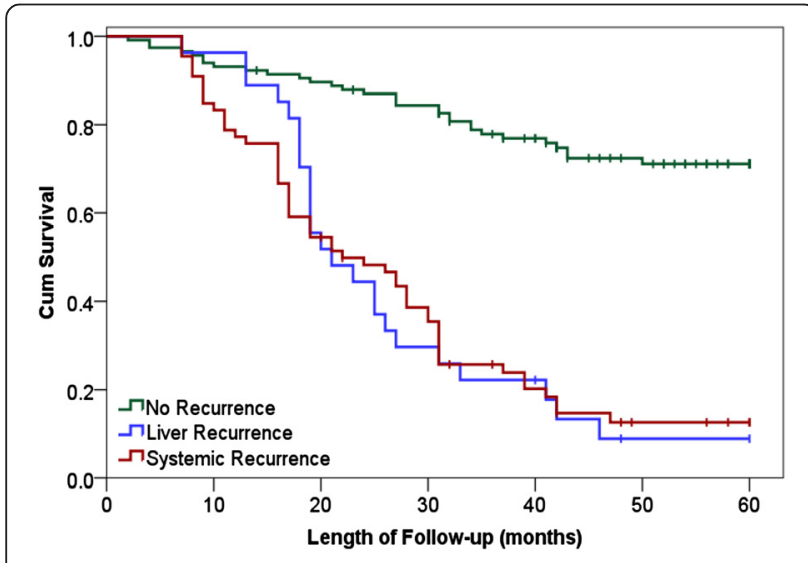

Figure 2 Overall patient survival in following LR for CLM. identify and stage primary CRC [34] as well as metastases [33] and has also been used to great effect in the staging of pancreatic [35] and lung [36] cancers. PET/CT in CLM patients may be associated with alterations in patient management in 34\% owing to disease upstaging [37]. Indeed, recent meta-analyses found FDG-PET was the most sensitive method for detection of liver metastases and extra-hepatic metastatic disease with sensitivities of $90 \%$ to $92 \%$ [15,17]. FDG-PET had a significantly higher pooled sensitivity and specificity for hepatic disease and EHD when compared to CT [38]. Moreover, PET/CT identifies more definitely normal and definitely abnormal lesions than with PET alone in CRC patients with improvements in staging and restaging [34]. Indeed, these changes in staging alter patient management in $25 \%$ of patients with the use of 18FDG-PET resulting in

Table 3 Analysis of factors predicting liver-only and systemic recurrence in patients following liver resection for CLM

\begin{tabular}{llll}
\hline & No recurrence & $\begin{array}{l}\text { Liver-only } \\
\text { recurrence } \\
\text { ( } \boldsymbol{n}=\mathbf{2 7})\end{array}$ & $\begin{array}{l}\text { Systemic } \\
\text { recurrence } \\
\text { ( } \boldsymbol{n}=\mathbf{6 6})\end{array}$ \\
\hline Number of metastases & 1 & 2 & $2.5^{*}$ \\
Median (quartiles) & $(1$ to 2$)$ & $(1$ to 2$)$ & $(2.3$ to 3.1$)$ \\
Largest tumour size & 2.9 & 2.7 & $3.9^{*}$ \\
Median (quartiles) & $(2.5$ to 3.2) & $(2.4$ to 3.2$)$ & $(3.6$ to 4.2$)$ \\
Male gender (\%) & 67 & $93^{* *}$ & 56 \\
Dukes C CRC & 64 & $96^{* *}$ & 74 \\
\hline
\end{tabular}

${ }^{*} P<0.05$ relative to no recurrence group; ${ }^{* *} P<0.05$ relative to no recurrence group. 
a reduction in unnecessary surgical interventions [39]. In a recent prospective study comparing 100 CLM patients staged by conventional techniques with $103 \mathrm{pa}$ tients staged with an additional FDG-PET, the rate of non-therapeutic laparotomies was significantly reduced in patients having preoperative FDG-PET. [38]. The results of this study were mirrored by a randomized study of 150 CLM patients selected for surgical resection by CT imaging alone or CT plus FDG-PET, which similarly demonstrated a significantly reduced rate of futile laparotomies [40]. Taken together with previous studies, it appears that liver recurrence following resection for colorectal metastasis is associated with T3-T4 disease, synchronous CLM, limited resection margins, Dukes C stage and male sex. Systemic recurrence appears to correlate with tumour size and tumour number.

\section{Conclusions}

In summary, it is possible to identify patients at high risk of early liver-only or systemic recurrence after LR for CLM. Such patients may be candidates for enhanced pre-operative staging to detect occult metastases and may also benefit from early post-operative imaging. A tailored approach to pre-operative staging in patients with CLM warrants further evaluation in a prospective study.

\section{Competing interests}

The authors declare that they have no competing interests.

\section{Authors' contributions}

RHB collated data and drafted manuscript. RPS, DFM, PM, JI, RM, and SRB designed the study and critically reviewed the manuscript. JH performed the statistical analysis. All authors read and approved the final manuscript.

\section{Acknowledgments}

No acknowledgments to make.

Received: 15 October 2014 Accepted: 16 March 2015

Published online: 01 April 2015

\section{References}

1. Wiering B, Vogel WV, Ruers TJ, Oyen WJ. Controversies in the management of colorectal liver metastases: role of PET and PET/CT. Dig Surg. 2008;25(6):413-20.

2. Mitry E, Guiu B, Cosconea S, Jooste V, Faivre J, Bouvier AM. Epidemiology, management and prognosis of colorectal cancer with lung metastases: a 30-year population-based study. Gut. 2010;59(10):1383-8.

3. Abdalla EK. Resection of colorectal liver metastases. J Gastrointest Surg. 2011;15(3):416-9.

4. Villeneuve PJ, Sundaresan RS. Surgical management of colorectal lung metastasis. Clin Colon Rectal Surg. 2009;22(4):233-41.

5. Fong Y, Fortner J, Sun RL, Brennan MF, Blumgart LH. Clinical score for predicting recurrence after hepatic resection for metastatic colorectal cancer: analysis of 1001 consecutive cases. Ann Surg. 1999;230(3):309-18. discussion 18-21.

6. Bradley AL, Chapman WC, Wright JK, Marsh JW, Geevarghese S, Blair KT, et al. Surgical experience with hepatic colorectal metastasis. Am Surg. 1999;65(6):560-6. discussion 6-7.

7. Sugihara K, Hojo K, Moriya Y, Yamasaki S, Kosuge T, Takayama T. Pattern of recurrence after hepatic resection for colorectal metastases. Br J Surg. 1993;80(8):1032-5.
8. Scheele J, Stangl R, Altendorf-Hofmann A. Hepatic metastases from colorectal carcinoma: impact of surgical resection on the natural history. Br J Surg. 1990;77(11):1241-6.

9. Goya T, Miyazawa N, Kondo H, Tsuchiya R, Naruke T, Suemasu K. Surgical resection of pulmonary metastases from colorectal cancer. 10-year follow-up. Cancer. 1989;64(7):1418-21.

10. McCormack PM, Burt ME, Bains MS, Martini N, Rusch WW, Ginsberg RJ. Lung resection for colorectal metastases. 10-year results. Arch Surg. 1992;127(12):1403-6.

11. Welter S, Jacobs J, Krbek T, Krebs B, Stamatis G. Long-term survival after repeated resection of pulmonary metastases from colorectal cancer. Ann Thorac Surg. 2007:84(1):203-10.

12. The International Registry of Lung Metastases. Long-term results of lung metastasectomy: prognostic analyses based on 5206 cases. J Thorac Cardiovasc Surg. 1997;113(1):37-49.

13. Malik HZ, Gomez D, Wong V, Al-Mukthar A, Toogood GJ, Lodge JP, et al. Predictors of early disease recurrence following hepatic resection for colorectal cancer metastasis. Eur J Surg Oncol. 2007;33(8):1003-9.

14. Niekel MC, Bipat S, Stoker J. Diagnostic imaging of colorectal liver metastases with CT, MR imaging, FDG PET, and/or FDG PET/CT: a meta-analysis of prospective studies including patients who have not previously undergone treatment. Radiology. 2010;257(3):674-84.

15. Floriani I, Torri V, Rulli E, Garavaglia D, Compagnoni A, Salvolini L, et al. Performance of imaging modalities in diagnosis of liver metastases from colorectal cancer: a systematic review and meta-analysis. J Magn Reson Imaging. 2010;31(1):19-31.

16. Knowles B, Welsh FK, Chandrakumaran K, John TG, Rees M. Detailed liver-specific imaging prior to pre-operative chemotherapy for colorectal liver metastases reduces intra-hepatic recurrence and the need for a repeat hepatectomy. HPB (Oxford). 2012;14(5):298-309.

17. Kinkel K, Lu Y, Both M, Warren RS, Thoeni RF. Detection of hepatic metastases from cancers of the gastrointestinal tract by using noninvasive imaging methods (US, CT, MR imaging, PET): a meta-analysis. Radiology. 2002;224(3):748-56.

18. Brachet D, Lermite E, Rouquette A, Lorimier G, Hamy A, Arnaud JP. Prognostic factors of survival in repeat liver resection for recurrent colorectal metastases: review of sixty-two cases treated at a single institution. Dis Colon Rectum. 2009;52(3):475-83.

19. Vigano L, Capussotti L, Lapointe R, Barroso E, Hubert C, Giuliante F, et al. Early recurrence after liver resection for colorectal metastases: risk factors, prognosis, and treatment. A LiverMetSurvey-based study of 6,025 patients. Ann Surg Oncol. 2014;21(4):1276-86.

20. Neeff H, Horth W, Makowiec F, Fischer E, Imdahl A, Hopt UT, et al. Outcome after resection of hepatic and pulmonary metastases of colorectal cancer. J Gastrointest Surg. 2009;13(10):1813-20.

21. Shah SA, Haddad R, Al-Sukhni W, Kim RD, Greig PD, Grant DR, et al. Surgical resection of hepatic and pulmonary metastases from colorectal carcinoma. J Am Coll Surg. 2006;202(3):468-75.

22. Headrick JR, Miller DL, Nagorney DM, Allen MS, Deschamps C, Trastek VF, et al. Surgical treatment of hepatic and pulmonary metastases from colon cancer. Ann Thorac Surg. 2001;71(3):975-9. discussion 9-80.

23. Khalil HI, Patterson SA, Panicek DM. Hepatic lesions deemed too small to characterize at CT: prevalence and importance in women with breast cancer. Radiology. 2005;235(3):872-8.

24. Seo HJ, Kim MJ, Lee JD, Chung WS, Kim YE. Gadoxetate disodium-enhanced magnetic resonance imaging versus contrast-enhanced 18 F-fluorodeoxyglucose positron emission tomography/computed tomography for the detection of colorectal liver metastases. Invest Radiol. 2011;46(9):548-55.

25. Donati OF, Reiner CS, Hany TF, Fornaro J, von Schulthess GK, Marincek B, et al. 18 F-FDG-PET and MRI in patients with malignancies of the liver and pancreas. Accuracy of retrospective multimodality image registration by using the CT-component of PET/CT. Nuklearmedizin. 2010;49(3):106-14.

26. Frankel TL, Gian RK, Jarnagin WR. Preoperative imaging for hepatic resection of colorectal cancer metastasis. J Gastrointest Oncol. 2012;3(1):11-8.

27. Marsman HA, van der Pool AE, Verheij J, Padmos J, Ten Kate FJ, Dwarkasing RS, et al. Hepatic steatosis assessment with CT or MRI in patients with colorectal liver metastases after neoadjuvant chemotherapy. J Surg Oncol. 2011;104(1):10-6.

28. Adam R, Pascal G, Azoulay D, Tanaka K, Castaing D, Bismuth H. Liver resection for colorectal metastases: the third hepatectomy. Ann Surg. 2003;238(6):871-83. discussion 83-4. 
29. Pessaux P, Lermite E, Brehant O, Tuech JJ, Lorimier G, Arnaud JP. Repeat hepatectomy for recurrent colorectal liver metastases. J Surg Oncol. 2006;93(1):1-7.

30. Thelen A, Jonas S, Benckert C, Schumacher G, Lopez-Hanninen E, Rudolph B, et al. Repeat liver resection for recurrent liver metastases from colorectal cancer. Eur J Surg Oncol. 2007;33(3):324-8.

31. John SK, Robinson SM, Rehman S, Harrison B, Vallance A, French JJ, et al. Prognostic factors and survival after resection of colorectal liver metastasis in the era of preoperative chemotherapy: an 11-year single-centre study. Dig Surg. 2013;30(4-6):293-301.

32. Lake ES, Wadhwani S, Subar D, Kauser A, Harris C, Chang D, et al. The influence of FDG PET-CT on the detection of extrahepatic disease in patients being considered for resection of colorectal liver metastasis. Ann R Coll Surg Engl. 2014;96(3):211-5

33. Papathanassiou D, Bruna-Muraille C, Liehn JC, Nguyen TD, Cure H. Positron emission tomography in oncology: present and future of PET and PET/CT. Crit Rev Oncol Hematol. 2009;72(3):239-54

34. Cohade C, Osman M, Leal J, Wahl RL. Direct comparison of (18)F-FDG PET and PET/CT in patients with colorectal carcinoma. J Nucl Med. 2003;44(11):1797-803.

35. Tann M, Sandrasegaran K, Jennings SG, Skandarajah A, McHenry L, Schmidt CM. Positron-emission tomography and computed tomography of cystic pancreatic masses. Clin Radiol. 2007;62(8):745-51.

36. Goerres GW, Kamel E, Seifert B, Burger C, Buck A, Hany TF, et al. Accuracy of image coregistration of pulmonary lesions in patients with non-small cell lung cancer using an integrated PET/CT system. J Nucl Med. 2002;43(11):1469-75.

37. Engledow AH, Skipworth JR, Pakzad F, Imber C, Ell PJ, Groves AM. The role of 18FDG PET/CT in the management of colorectal liver metastases. HPB (Oxford). 2012;14(1):20-5.

38. Wiering B, Krabbe PF, Dekker HM, Oyen WJ, Ruers TJ. The role of FDG-PET in the selection of patients with colorectal liver metastases. Ann Surg Oncol. 2007;14(2):771-9.

39. Chua SC, Groves AM, Kayani I, Menezes L, Gacinovic S, Du Y, et al. The impact of 18 F-FDG PET/CT in patients with liver metastases. Eur J Nucl Med Mol Imaging. 2007;34(12):1906-14.

40. Ruers TJ, Wiering B, van der Sijp JR, Roumen RM, de Jong KP, Comans EF, et al. Improved selection of patients for hepatic surgery of colorectal liver metastases with (18)F-FDG PET: a randomized study. J Nucl Med. 2009;50(7):1036-41.

\section{Submit your next manuscript to BioMed Central and take full advantage of:}

- Convenient online submission

- Thorough peer review

- No space constraints or color figure charges

- Immediate publication on acceptance

- Inclusion in PubMed, CAS, Scopus and Google Scholar

- Research which is freely available for redistribution 